\title{
Agir comunicativo, redes de conversação e coordenação em serviç̧os de saúde: uma perspectiva teórico-metodologica"
}

Juliano de Carvalho Lima ${ }^{1}$

Francisco Javier Uribe Rivera ${ }^{2}$

LIMA, M.C.; RIVERA, F.J.U. Communicative action, networks of conversation and coordination in healthcare services: a theoretical and methodological perspective. Interface - Comunic., Saude, Educ., v.13, n.31, p.329-42, out./dez. 2009.

This paper discusses a theoretical and methodological approach for studies within the field of integration of healthcare services. The intersubjective aspects of the coordination processes are emphasized. The discussion starts from the assumption that the coordination of healthcare actions and services, which is a process central to integration, is essentially a communicative action. Among the methodological aspects, the potential of conversation analysis is highlighted as a tool for analyzing the interactions that are established within the processes of coordinating healthcare actions and services.

Keywords: Coordination. Communication. Integration of healthcare services.

Conversation analysis. Intersetorial action.
Neste artigo discute-se uma abordagem teórico-metodológica para estudos na área da integração de serviços de saúde, destacando o aspecto intersubjetivo dos processos de coordenação. Parte-se do pressuposto de que a coordenação de ações e serviços de saúde, processo central da integração, é essencialmente uma ação comunicativa. Entre os aspectos metodológicos destacam-se as potencialidades da Análise de Conversações (AC) enquanto ferramenta para analisar as interações que se estabelecem nos processos de coordenação de ações e serviços de saúde.

Palavras-chave: Coordenação. Comunicação. Integração de serviços de saúde. Análise de conversação. Ação intersetorial.

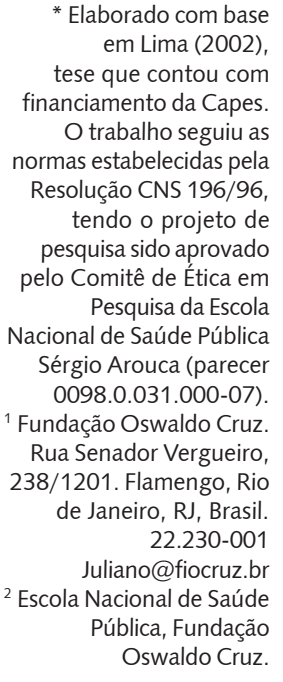

* Elaborado com base tese que contou com financiamento da Capes. o seguiu as Resolução CNS 196/96, tendo o projeto de pesquisa sido aprovado Pesquisa da Escola nal de Saúde Pública Sérgio Arouca (parecer 0098.0.031.000-07).

Rua Senador Vergueiro, 8/1201. Flamengo, Rio Janeiro, RJ, Brasil. Juliano@fiocruz.br Pública, Fundação Oswaldo Cruz. 


\section{Introdução}

Embora tenha sido criado com vistas à constituição de redes de serviços capazes de permitir o acesso de qualidade a todos, o Sistema Único de Saúde (SUS) ainda é caracterizado como um sistema fragmentado, com distribuição desigual dos recursos e articulação insuficiente entre os serviços. Em face dos problemas de fragmentação das ações assistenciais, Hartz e Contandriopoulos (2004) consideram que a integração dos serviços aparece como um atributo inerente às reformas de políticas públicas e torna-se eixo prioritário de investigação e avaliação dos serviços e sistemas de saúde.

É com base nessa compreensão que se discute, neste trabalho, uma perspectiva teóricometodológica para estudos na área de integração de serviços de saúde, tendo como pressuposto a ideia de que a coordenação das ações de saúde é essencialmente uma ação comunicativa.

O ponto de partida é uma revisão sobre integração em sistemas de serviços de saúde, onde se busca uma aproximação conceitual entre coordenação, integralidade e comunicação. Nesta revisão enfatiza-se a emergência de uma visão relacional e dialógica da coordenação. A partir de então, faz-se uma reconstrução comunicativa da coordenaç̧ão, utilizando-se elementos da Teoria do Agir Comunicativo (Habermas, 2002a, 2002b, 2001), da Teoria dos Atos de Fala (Austin, 1965) e da Teoria da Conversação (Echeverria, 1997). Propõe-se que estudos baseados na análise de Redes de Conversação são potentes para esclarecer aspectos importantes destes processos e orientar sobre novas formas de coordenar serviços de saúde. Como conclusão, apontam-se perspectivas metodológicas para a realização de estudos baseados neste enfoque.

\section{Coordenação, integração e comunicação em sistemas de serviços de saúde}

Para Longest e Klingensmith (1988), a coordenação representa o principal instrumento pelo qual os gerentes articulam e integram as várias pessoas e unidades dentro das organizações e integram suas organizações com outras. "Se as ligações não são efetivas, as organizações podem se tornar fragmentadas, fracionadas e isoladas, com concomitante declínio da performance" (Longest, Klingensmith, 1988, p.235). Para os autores, o conceito-chave para se discutir a questão da coordenação é a interdependência, caracterizada em função das relações entre unidades e indivíduos.

$\mathrm{Na}$ discussão sobre mecanismos de coordenação interorganizacional, os autores destacam que "organizações de atenção à saúde vivenciam experiências de interdependências com outras organizações de saúde ou com outros elementos no seu ambiente externo, como, por exemplo, distintos níveis de governo, fornecedores, pagadores e assim por diante" (Longest, Klingensmith, 1988, p.245).

Mitchell e Shortell (2000) definem coordenação como o gerenciamento de um sistema de intercâmbios. Para os autores, um adequado grau de coordenação pode ampliar e melhorar a comunicação, reduzir incertezas e evitar conflitos. Embora os conflitos sejam parte inerente a qualquer organização social, eles surgem, sobretudo, quando diversas organizações com interesses diversos tentam trabalhar juntas.

Hartz e Contandriopoulos (2004, p.332) veem a coordenação como o propósito principal dos processos de integração de serviços de saúde. "Num sentido mais amplo, a integração em saúde é um processo que consiste em criar e manter uma governança comum de atores e organizações autônomas, com o propósito de coordenar sua interdependência, permitindo-lhes cooperar para a realização de um projeto (clínico) coletivo".

Ao pensar-se o sistema de serviços de saúde como uma rede coordenada capaz de garantir o acesso e a continuidade do cuidado, é importante ter em conta que as ligações entre os nós desta rede somente podem ocorrer mediante o estabelecimento de uma rede intrincada de interações entre: aqueles responsáveis pela organização do sistema (gestores), os responsáveis pela organização e produção dos serviços (prestadores e profissionais) e os cidadãos, que podem ser considerados como os três sujeitos genéricos da coordenação/ integração em sistemas de serviços de saúde. Entende-se, assim, que as formas de organizar a atenção à saúde são expressão das relações e das interações entre estes três atores centrais. A gestão é entendida neste trabalho como um processo político de produzir contratualidades entre os diferentes atores sociais com vistas à organização das ações de saúde. 
Segundo Feuerwerker et al. (2000, p.10), "apesar de nesse processo [constituição de redes de serviços de saúde] estarem envolvidas instituições e projetos, são sempre pessoas que se articulam e conectam. São sempre pessoas que constroem vínculos. É a unidade básica do vínculo, a relação entre sujeitos, que vai conformar uma rede".

Rovere $(1998$, p.30) também reforça a concepção acima.

\begin{abstract}
Redes são redes de pessoas, se conectam ou vinculam pessoas, ainda que esta pessoa seja o diretor da instituição e se relacione com seu cargo incluído, porém não se conectam cargos entre si, não se conectam instituições entre si, não se conectam computadores entre si, se conectam pessoas. Por isto é que se diz que rede é a linguagem dos vínculos.
\end{abstract}

Assim, as relações interorganizacionais, sempre enfatizadas nas discussões sobre sistemas integrados, somente se dão, na prática, a partir de relações interpessoais.

Mas apesar desta constatação, são poucos os estudos que buscam apreender o modo como se dão estas interações. Predominam análises voltadas para medir a integração em termos de troca de recursos, de encaminhamentos de pacientes, de protocolos, mas poucos são os estudos voltados para a análise do papel da comunicação interpessoal e do modo como ela atua no interior do sistema.

Estudos recentes no campo da saúde têm enfatizado a emergência de uma perspectiva diferente na análise de processos de coordenação intra e interorganizacionais. Safran, Miller e Beckman (2005) chamam a atenção para o que denominam dimensões organizacionais de cuidados centrados no relacionamento. Tal perspectiva enfatiza a importância das relações interpessoais e da cultura de solidariedade para o sucesso organizacional e, especialmente, o papel de redes de conversações colaborativas.

Gittel (2002a, 2002b) e Gittel e Weiss (2004) enfatizam, em seus estudos sobre a microdinâmica da coordenação entre serviços de saúde, que o desenho de certos mecanismos podem facilitar a coordenação, mas esta é fundamentalmente um processo de interação entre os participantes. Embora a coordenação possa se dar por meio de uma grande variedade de mecanismos, tais como programação de tarefas, padronização e estabelecimento de rotinas, estes são mais apropriados a interdependências do tipo sequencial ou linear, mas não são suficientes em áreas onde prevalecem atividades que são reciprocamente interdependentes, onde há elevado grau de incerteza e onde o tempo é escasso, como é o caso da provisão de serviços de saúde.

Para dar conta deste padrão de interdependências, Gittel tem advogado por uma determinada perspectiva da coordenação, a qual denomina coordenação relacional (relational coordination). Esta forma de coordenação diferencia-se de outras identificadas na teoria organizacional por referir-se mais às interações entre os participantes do que aos mecanismos que dão suporte a estas interações.

Segundo essa abordagem, a comunicação possui um papel preponderante. A coordenação relacional reflete o papel que a comunicação frequente, oportuna, precisa e centrada na solução de problema tem nos processos de coordenação (Gittel, 2002a).

Resultados de seus estudos mostraram que rotinas, gerenciamento de casos, reuniões de equipe e coordenação relacional têm efeitos positivos na eficácia dos serviços. Mas, além disso, os autores concluem que os mecanismos formais de coordenação melhoram a performance do serviço pelo incremento do nível de coordenação relacional, ou seja, dos processos de interação.

Em outro estudo com foco nas relações entre prestadores de serviços no cuidado pós-cirúrgico e utilizando as mesmas dimensões da coordenaç̧ão relacional, Gittel (2002b) testou duas hipóteses: 1) a coordenação relacional entre prestadores de serviços aumenta a satisfação dos usuários, independente dos efeitos diretos da relação usuário-provedor; b) a coordenação relacional entre prestadores aumenta a intenção dos usuários de recomendar o serviço a outros, independente dos efeitos diretos da relação usuário-provedor.

Os resultados do estudo mostraram que fortes relações entre provedores de serviços de saúde têm efeito direto no incremento da satisfação dos usuários e na sua fidelidade aos serviços, devido ao recebimento de um tratamento mais coordenado. Além disso, relações entre os prestadores ajudam os serviços a desenvolverem relações mais efetivas com os próprios usuários, contribuindo assim para a satisfação. 
Com base em um estudo realizado em um centro de atendimento ao trauma nos Estados Unidos, Faraj e Xiao (2006) argumentam que, diferente de outras situações, as organizações de resposta rápida (fast-response organizations), como as emergências hospitalares, operam com elevado grau de incerteza e com processos rápidos de tomada de decisão.

Para essas organizações, os autores desenvolvem uma abordagem que enfatiza o que denominam coordenação da expertise e coordenação dialógica, uma vez que essas organizações são menos dependentes de arranjos estruturais de coordenação e são mais contingentes na integração do conhecimento.

Entre as práticas de coordenação da expertise, Faraj e Xiao (2006) incluem mecanismos como: elaboração de protocolos, arranjos flexíveis de composição de equipes (ora em função de um paciente, ora em função de um procedimento, ora em função do plantão), formação de comunidades de práticas e mecanismos de compartilhamento de conhecimento, como estudos de casos, seminários, entre outros.

Já a coordenação dialógica entraria em cena, sobretudo, como respostas situadas a trajetórias inesperadas dos pacientes. Na coordenação dialógica, são quatro as práticas principais: 1) a geração de consenso, que ocorre especialmente quando a equipe se vê obrigada a se reunir e discutir determinado caso que não está seguindo a trajetória esperada; 2 ) a intervenção "transfronteira", que ocorre geralmente quando a segurança de um paciente está comprometida, o que permite a intervenção de profissionais de outras áreas no trabalho sob responsabilidade de outros; 3 ) a contestação epistêmica, que diz respeito a conversações que emergem entre as várias comunidades de prática quando da diferença de opinião acerca de determinada situação; 4) a quebra de protocolos como uma prática de coordenação, sobretudo em situações especiais e de grande risco.

O aspecto mais relevante do trabalho de Faraj e Xiao (2006) é a conclusão de que, em determinadas organizações, onde o conhecimento, a incerteza e a interdependência variável são características, as abordagens que enfatizam o desenvolvimento de mecanismos de coordenação pré-especificados não são adequadas. Nestas organizações os mecanismos de coordenação não são facilmente especificados e são altamente contingentes. Os estudos de Faraj e Xiao (2006) dão suporte para uma conceituação relacional da coordenação como um fenômeno emergente.

Também para Franco (2006), a organização da atenção à saúde se dá fundamentalmente pelas relações, pelas conexões que se estabelecem entre pessoas que estão em situação e se formam em linhas de fluxos horizontais por dentro das organizações.

Ao observarmos o funcionamento das redes de cuidado do SUS, verificamos que, entre as diversas unidades, seja da equipe de saúde da família, unidades básicas, serviços de especialidades, rede hospitalar e mesmo o atendimento pré-hospitalar, trabalham comunicando-se mutuamente, em um processo que de longe pode se verificar que é um funcionamento em rede. (Franco, 2006, p.130)

Para Franco (2006), as redes de serviços de saúde e as redes de produção de cuidados seriam sistemas abertos de conexão, cuja produção se dá sem que haja um eixo estruturado sobre o qual se organiza. São as relações que vão construindo o meio social em que se inserem os atores. A produção da atenção à saúde se dá, nesta perspectiva, a partir de múltiplas conexões e fluxos, que criam linhas de contato entre atores sociais que são a fonte de produção da atenção.

Artmann (2002) e Artmann e Rivera (2003), ao olharem para a rede de serviços hospitalares, buscam identificar instrumentos que possibilitem estruturar esta rede a partir dos custos de oportunidade, da comunicação e da solidariedade. A proposta de planificação apresentada pelos autores, a démarche stratégique, é um sistema de análise da missão dos serviços hospitalares que valoriza as sinergias e parcerias. Parte de um olhar abrangente sobre a rede, o que inclui a realização de um diagnóstico administrativo e epidemiológico da área onde o hospital está inserido. Assim como em autores discutidos anteriormente, a proposta justifica-se pelo elevado grau de interdependência nos processos de atenção. Para Artmann (2002), a diversificação crescente dos processos de atenção, o seu caráter transversal e o amplo e crescente número de atores mobilizados neste processo de trabalho demonstram o elevado grau de interdependência que apresenta o sistema. 
O importante a se destacar em relação à abordagem proposta é que ela se opõe a uma perspectiva normativa e tecnocrática de definição de diretrizes e estratégias hospitalares, apostando no desenvolvimento de processos comunicativos e de negociação externos ao hospital que redundem em acordos relativos aos projetos assistenciais pertinentes à rede de serviços. Nesta perspectiva, Artmann e Rivera (2003) se aproximam de Franco (2006), para quem as linhas assistenciais e os projetos assistenciais inseridos nelas são resultantes de um pacto produzido a partir do desejo, da adesão ao projeto, de vontade política, recursos cognitivos e materiais, e que constitui o centro nervoso de viabilização da proposta.

A revisão realizada acima traz, para o debate, importantes elementos no que diz respeito à tentativa de aproximar as ideias de coordenação, integração e comunicação.

Como visto, a coordenação está no centro das discussões recentes sobre a constituição de sistemas integrados de serviços de saúde. As várias abordagens ao tema, incluindo as várias denominações e experiências, como constituição de redes, gerenciamento de casos, continuidade do cuidado, integração clínica, têm em comum o objetivo de tentar lidar com as interdependências do sistema. Interdependência é a questão-chave, pois se não há interdependência, não há nada a ser coordenado. Esta deve, portanto, ser analisada em termos de atores que desenvolvem tarefas interdependentes e que requerem recursos de vários tipos. Assim, os atores em uma organização se deparam com problemas de coordenação que surgem das dependências, que dificultam o desempenho das atividades

A coordenação é abordada como um meio para incrementar alguns dos objetivos do sistema de saúde, dos quais destacam-se a integração dos serviços e a integralidade da atenção. A seguir, apontamos alguns dos resultados esperados em sistemas de serviços com elevado grau de coordenação: garantir o acesso e a continuidade; evitar a sujeição do paciente a procedimentos desnecessários; evitar a duplicação de procedimentos ou exames, e agilizar o atendimento.

São muitas as abordagens e as metodologias voltadas para a análise da coordenação em sistemas de serviços de saúde. Boa parte dos estudos assume uma perspectiva estrutural-funcionalista, destacando as relações interorganizacionais e enfatizando a modificação das fronteiras das organizações. Uma abordagem feita exclusivamente sob esta perspectiva termina por apagar ou ocultar as relações entre os sujeitos em interação que, em último caso, é o que produz de fato a coordenação das ações.

No entanto, recentemente, uma série de trabalhos tem reconhecido cada vez mais o caráter relacional, micropolítico e dialógico, da organização de redes de serviços de saúde. É possível falar, parafraseando Habermas, em uma "guinada para a comunicação", a partir do momento em que temas como integralidade e coordenação passam a se constituir elementos essenciais para a criação de novas possibilidades para o campo da saúde.

A construção da integralidade passa pela instituição de estruturas e mecanismos reguladores dos fluxos de usuários entre os serviços, mas passa fundamentalmente pela mudança nos modos de interação entre profissionais e usuários e entre as equipes de profissionais e gestores. Como essa interação se dá, fundamentalmente, por meio da linguagem, isso exige novos processos de comunicação. Neste sentido, busca-se, a seguir, fundamentar uma abordagem comunicativa para análise da coordenação, tomando por base elementos da Teoria do Agir Comunicativo, da Teoria dos Atos de Fala e da Teoria da Conversação.

\section{Comunicação e coordenação de ações}

Segundo Maturana (2001), é possível falar em consenso ou condutas consensuais toda vez que se faz referência a condutas ou coordenações de condutas que se estabelecem como resultado do fato de as pessoas estarem juntas, em interações recorrentes. A coordenação de ações tem um caráter eminentemente comunicativo. "A linguagem é um modo de viver juntos num fluir de coordenação consensual de coordenações consensuais de comportamentos, e é como tal um domínio de coordenações de coordenações de ações" (Maturana, 2001, p.178). 


\section{Teoria do Agir Comunicativo e coordenação de ações}

Habermas (2002a) afirma que é possível entender uma interação como a solução do problema de como os planos de ação de diversos atores podem ser coordenados de modo que as ações de um possam ser "ligadas" às ações do outro.

A necessidade de ligação decorre do interesse que cada ator possa ter de cumprir seu plano de ação. "O problema de coordenação da ação verifica-se logo que um agente consiga materializar o seu plano de uma forma apenas interativa, ou seja, com a ajuda da ação de pelo menos um outro agente (ou da sua opção de se abster de agir)" (Habermas, 2002a, p.110).

Nos sistemas de saúde, essa é justamente a situação. O adequado atendimento às necessidades da população somente é possível na medida em que as várias pessoas que atuam nos serviços (gestores, prestadores, profissionais e usuários) interajam umas com as outras.

Segundo Habermas (2001, 2002a), os mecanismos de coordenação de ação utilizados distinguem dois tipos de interação, segundo o uso que é feito da linguagem. Quando a linguagem é utilizada apenas como meio de transmissão de informação com vistas a um fim, fala-se em ação estratégica. Já quando ela é utilizada como fonte de integração social, fala-se em ação comunicativa.

No caso da ação comunicativa, " a força consensual dos processos lingüísticos de se obter entendimento, ou seja, as energias vinculativas da própria linguagem - torna-se eficaz para a coordenação de ações" (Habermas, 2002a, p.110). Já no primeiro caso, o da ação estratégica, o efeito coordenador é dependente da influência exercida pelos atores em interação, não apenas sobre a situação da ação, mas também sobre o outro.

Na ação comunicativa, pressupõe-se a existência de uma base de pretensões de validade mutuamente reconhecidas. Os agentes participantes tentam adequar os seus respectivos planos cooperativamente, dentro do horizonte de um mundo da vida partilhado e com base em interpretações comuns de situação.

O agir comunicativo impele os indivíduos a abandonarem o egocentrismo de um cálculo orientado exclusivamente para o seu próprio sucesso. Sob o aspecto funcional de entendimento, a ação comunicativa serve à tradição e à renovação da cultura; sob o aspecto da socialização, serve à formação das personalidades individuais; e sob o aspecto da coordenação da ação, serve à integração social e à criação de solidariedade.

A integração social, mediada pela linguagem,

cuida que as ações sejam coordenadas através de relações interpessoais legitimamente reguladas e da continuidade da identidade dos grupos em um grau que baste à prática comunicativa cotidiana. A coordenação das ações e a estabilização das identidades de grupo têm aqui sua medida na solidariedade dos membros. (Habermas, 2001, p.200)

O agir comunicativo distingue-se do agir estratégico porque uma coordenação da ação bemsucedida não depende da racionalidade teleológica das orientações da ação, mas da força racionalmente motivadora de realizações de entendimento, isto é, de uma racionalidade que se manifesta nas condições para um consenso obtido comunicativamente (Aragão, 2002).

Para uma efetiva coordenação da ação, é necessário um agir baseado na busca do entendimento (agir comunicativo), assentado na capacidade de os participantes da interação produzirem um consenso fundamentado argumentativamente sobre pretensões de validez criticáveis, que irá motivar suas ações e promover a emancipação frente à dominação política e a liberação do homem para a reflexão crítica. Tal perspectiva não elimina e nem pretende eliminar o conflito. Busca sua solução via uma interação dialógica baseada em argumentos.

Voltando o olhar para os sistemas de serviços de saúde, compreende-se que a superação da fragmentação e a ampliação do acesso dependem de uma integração social por meio de valores, normas e processos de entendimento entre os implicados na provisão de serviços de saúde. Tendo em vista as atuais discussões sobre a integração de serviços no Brasil, em especial as que advogam a 
necessidade de uma perspectiva solidária de regionalização, deduz-se que as relações intergestores têm se dado mais com base na competição por recursos escassos e na disputa pelo poder (agir estratégico).

A Teoria da Ação Comunicativa apresenta um caminho para pensar a transformação da prática cotidiana, inclusive nos pequenos espaços institucionais, como um sistema de serviços de saúde, onde se evoluiria de uma perspectiva autoritária, fragmentada e individualista para uma visão democrática, integrada, baseada no trabalho coletivo, na solidariedade, na comunicação, no confronto de argumentações e na busca do consenso.

As reflexões trazidas pela Teoria do Agir Comunicativo fornecem uma base de compreensão dos processos de coordenação baseados na interação linguística que se dá entre sujeitos que, para materializarem seus planos, precisam da ação (ou não ação) de outro. Assim, a construção de um modelo teórico capaz de orientar a análise da coordenação em sistemas de saúde, exige um aprofundamento sobre a questão de como se dão, cotidianamente, os diálogos e como esses são utilizados nos processos de coordenação.

Nesse sentido, algumas ideias como atos de fala (Austin, 1965) e conversação (Echeverria, 1997, 2000) são úteis para a análise das atividades de coordenação.

\section{Atos de fala, conversação e coordenação}

Flores (1989) e Echeverria $(1997,2000)$ analisam as organizações enquanto fenômenos linguísticos. Esta visão das organizações e do papel central das conversações decorre do papel gerativo da linguagem.

Quando um sujeito fala, não apenas descreve a realidade pura e simplesmente; ele gera realidade. A concepção de linguagem como ação supera a visão de que ela seria algo passivo, descritivo, onde a realidade viria primeiro e a linguagem serviria para descrevê-la.

Segundo Austin (1965), distinguem-se dois tipos de proferimentos: os constatativos e os performativos. Os primeiros são aqueles que descrevem ou relatam um estado ou uma situação, e que, por isso, se submetem ao critério de verificabilidade, isto é, podem ser rotulados de verdadeiros ou falsos. Já os enunciados performativos, são proferimentos que realizam uma ação, executam atos. Um Ato de Fala é, pois, um proferimento linguístico realizativo.

Dentro dessa perspectiva de linguagem como ação, Echeverria (1997), adaptando a classificação original de Austin (1965), distingue três categorias de enunciados de fala: as afirmações, as declarações e as promessas.

No caso das afirmações, a palavra adequa-se ao mundo. Geralmente, as afirmações correspondem a descrições da realidade. Tratam-se de proposições acerca das observações feitas por alguém sobre algo no mundo objetivo. Quando alguém diz: "essa caneta é vermelha", está fazendo uma afirmação.

Já as declarações são bem distintas das afirmações. "Quando fazemos declarações não falamos sobre o mundo, geramos um novo mundo para nós" (Echeverria, 1997, p.75). Quando um juiz diz "Inocente", ou quando o gerente diz "Você está despedido", os sujeitos não estão se referindo a algo que passa no mundo, mas estão criando uma nova realidade, onde um suspeito se torna livre e um trabalhador desempregado.

Por fim, as promessas implicam um compromisso manifesto mútuo. Este compromisso constitutivo de uma promessa não é apenas um compromisso individual, mas também social.

A realização desses três atos de fala básicos apresenta relação com as pretensões de validade levantadas por um sujeito em comunicação com outros. Quando se faz uma afirmação, o falante compromete-se com a veracidade do que diz. Ao fazer uma declaração, compromete-se com a validez do que foi declarado, o que está em relação com as normas sociais construídas pela sociedade. Por fim, quando se faz uma promessa, compromete-se com a sinceridade da promessa e com a competência para cumpri-la.

O segundo conceito importante para a abordagem comunicativa da coordenação é o de conversação. Esta é, segundo Flores (1989), a unidade mínima de interação social orientada para a execução com êxito de ações. Para Marcuschi (2005), a conversação é uma interação verbal centrada, 
que se desenvolve durante o tempo em que, pelo menos, dois interlocutores voltam sua atenção visual e cognitiva para uma tarefa comum. Deste modo, os atos de fala são subcomponentes da conversação. Ou seja, uma conversação envolve vários proferimentos linguísticos aceitos por dois ou mais interlocutores em uma interação voltada para uma atividade comum.

Para Echeverria (1997), a conversação é o gênero básico da interação humana e sua característica importante advém do fato de ela incluir não apenas o falar, mas também o escutar. Está-se diante de uma conversação quando o escutar e o falar estão "interatuando" juntos. Em uma conversação, a escuta é ativa, na medida em que cada interlocutor interpreta os Atos de Fala a sua maneira. Por isso, é possível dizer que a escuta valida a fala, sendo, portanto, uma precondição da fala efetiva.

Echeverria (1997) traz uma tipologia que contempla quatro tipos de conversações: a conversação de juízos pessoais; a conversação para a coordenação de ações; a conversação para possíveis ações; e a conversação para possíveis conversações.

Na conversação de juízos pessoais, entra-se numa cadeia de juízos por meio dos quais busca-se interpretar o que ocorreu e as consequências derivadas do fato. Trata-se de uma ação que se destina a dar sentido aos acontecimentos, trata-se de uma ação reflexiva.

Já as conversações para coordenação de ações são aquelas que levam as pessoas a atuarem sobre os problemas buscando superá-los. Não se trata de uma ação puramente reflexiva, portanto, mas sim de uma ação gerativa.

As conversações para possíveis ações não estão orientadas para enfrentar os problemas em questão, mas sim para a ação de especular e explorar novas ações possíveis, novas possibilidades que podem ou não levar à coordenação da ação.

E, por fim, as conversações para possíveis conversações são aquelas que ocorrem quando se julga não ser possível conversar diretamente com alguém acerca de algo.

Ao atribuir-se à coordenação um caráter preponderantemente comunicacional, conforme defendido até aqui, as conversações e seus subcomponentes, os atos de fala, passam a ter papel fundamental na construção de um modelo de análise de processos de coordenação e integração em serviços de saúde.

Segundo Echeverria (2000, p.75): "Se examinamos agora as atividades de coordenação, constatamos que estas são também estritamente conversacionais. E mais, a linguagem é a grande ferramenta que possuem os seres humanos para coordenar ações entre si e para coordenar inclusive a forma como se coordenam ações".

Interessa particularmente a noção de conversação para coordenação de ações. O objetivo deste tipo de conversação é fazer com que algo aconteça, é intervir sobre o estado atual das coisas. $O$ fundamental nestas conversações é a tentativa de modificar aquilo que produziu o problema ou dar conta de suas consequências.

Nesse sentido, os atos de fala do tipo declaração e, sobretudo, promessa, cumprem um papel central. "As promessas são, por excelência, aqueles atos linguìsticos que nos permitem coordenar ações com outros. Quando alguém faz uma promessa, ele ou ela se compromete perante o outro a executar alguma ação no futuro" (Echeverria, 1997, p.92).

Segundo Echeverria (1997), são as declarações e as promessas que permitem que surjam novas realidades. Um dos pontos mais importantes tratados pelo referido autor diz respeito à ideia de que esse tipo de ação reveste-se de especial importância e é o modo por meio do qual se faz possível a resolução de problemas coletivos.

"No mundo de hoje não é possível viver na completa autosuficiência. Somos dependentes uns dos outros. Temos que aprender, portanto, a colaborar com os outros, a apoiarmos mutuamente, a coordenar ações juntos" (Echeverria, 1997, p.237).

É a capacidade de as pessoas em interação realizarem, aceitarem e cumprirem com os compromissos que dá a possibilidade de ampliação de coordenação das ações. Pelo caráter fortemente realizativo das declarações, estas cumprem papel primordial na coordenação na medida em que se traduz imediatamente em ação concreta de mudança da realidade.

A seguir, busca-se ilustrar uma rápida conversação com vistas à coordenação de ações em serviços de saúde. 

A: "Tenho um paciente grave e preciso de uma vaga em UTI" (Afirmação)
$B$ : "Vou verificar junto ao Hospital X" (Oferta de promessa)
A: "OK" (Aceite da promessa)
B: "A vaga de UTI no Hospital X é sua" (Declaração/efetivação da promessa)

Esta breve conversação mostra o papel desempenhado por cada ato de fala para coordenar ações com vistas ao bem-estar do hipotético paciente.

Neste sentido, surge outro conceito importante para uma abordagem comunicativa da coordenação. Trata-se do conceito de competência conversacional (Habermas, 2001; Echeverria, 2000, 1997). Ao reconhecer-se o caráter gerativo da linguagem, percebe-se quanto o comunicar pode ser mais ou menos efetivo de acordo com "como" se dá a comunicação. A precariedade da comunicação pode resultar em desentendimento, em desconfiança, em distorção de ideias, em resultados insatisfatórios em relação ao um acordo e em situações de dominação.

Por competência comunicativa, Habermas (2001) entende a capacidade de um falante orientado para o entendimento, de forma a conceber uma frase corretamente formulada em relação à realidade. Isso implica o cumprimento das seguintes condições:

. Atender às exigências de inteligibilidade da frase proferida.

. Cumprir com as condições de verdade da proposição ou com os pressupostos existenciais do conteúdo proposicional.

. Expressar as suas intenções de modo que a expressão linguística apresentada represente de fato aquilo que se pretende.

. Desempenhar o ato de fala em conformidade com as formas reconhecidas ou com as imagens aceites de nós-próprios (de forma a que o ouvinte possa confiar no falante).

Já Echeverria (2000, p.144) depreende, do conjunto de atos de fala, um conjunto de competências correspondentes. "Cada um dos atos de linguagem pode realizar-se de diversas maneiras e com graus de competência distintos". As competências conversacionais têm um caráter potencializador em relação a competências específicas. Muitas dessas últimas dependem da eficiência das competências conversacionais.

Por fim, as competências conversacionais possuem outros dois processos conversacionais complementares: o processo de aprendizagem e o processo de reflexão prática. Esses processos conversacionais estão na base da capacidade humana para adquirir qualquer outro tipo de competência e de melhorar aquelas que já possuem.

Sob a ideia de conversações para coordenação de ações e competências conversacionais, há um grande potencial para se pensar a questão da coordenação em sistemas e serviços de saúde, uma vez que, como se tem sustentado até aqui, a coordenação da ação é uma atividade essencialmente linguística e se faz por meio dos atos de fala que se estabelecem nos processos de interação com vistas a gerenciar atividades interdependentes.

\section{Redes de conversação, coordenação e integração de sistemas/serviços de saúde}

Com base nas contribuições da Teoria do Agir Comunicativo, da Teoria dos Atos de Fala e da Teoria da Conversação, alguns elementos podem ser apreendidos no sentido de conformar um modelo teórico que privilegie os processos de interação entre os sujeitos envolvidos na coordenação de ações em sistemas de serviços de saúde.

A partir da perspectiva de sistemas integrados de Hartz e Contandriopoulos (2004), que apresenta cinco dimensões inter-relacionadas - integração dos cuidados, integração da equipe clínica, integração funcional, integração normativa e integração sistêmica - é possível representar processos que envolvem múltiplos atores que necessitam coordenar atividades que são interdependentes, focando a análise nas 
interações que se dão entre eles. Como são os processos comunicacionais que sustentam essas interações, é possível analisá-las no conjunto das dimensões apresentadas ou em cada uma separadamente.

Cada uma dessas dimensões apresenta atividades interdependentes que demandam mecanismos e processos eficazes de coordenação. É o modo de funcionamento destes mecanismos e processos que irá garantir ou não a integração em cada uma das dimensões e, consequentemente, no sistema de serviços de saúde como um todo.

Com base nas discussões feitas anteriormente, depreende-se que, no interior de cada uma daquelas dimensões dos sistemas integrados, operam mecanismos e processos de coordenação que estão ancorados, sobretudo, em conversações que se estabelecem entre os distintos atores.

Desse modo, para cada dimensão de um sistema integrado de saúde, pode-se adotar um modelo de análise baseado na inter-relação entre interdependência, coordenação e integração, cujo eixo estruturante é uma dinâmica rede de conversações. Ou seja, é a rede de conversações que se estabelece entre os atores em situação, gestores, prestadores/ profissionais e usuários, que garante o vínculo entre a interdependência, a coordenação e a integração (Figura 1).

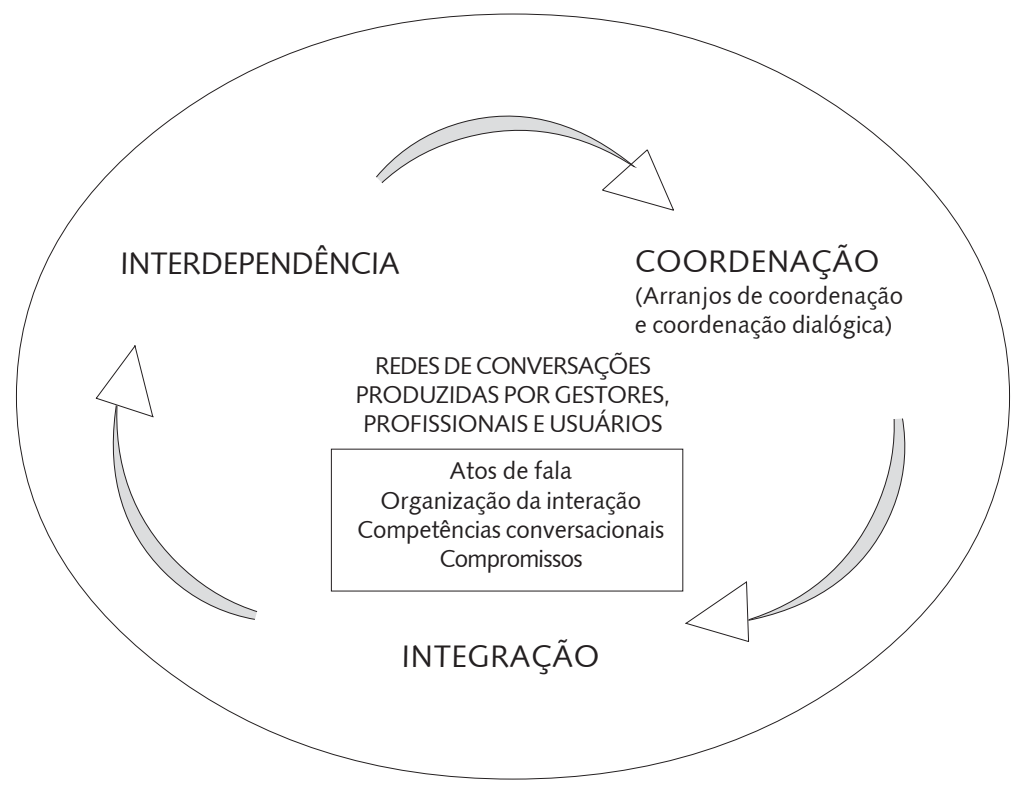

Figura 1. Compreensão comunicativa da inter-relação entre interdependência, coordenação e integração.

A noção de rede traz, no plano técnico-operacional, a ideia de fluxo, de circulação, como, por exemplo, as redes de transportes, de água e esgoto, de telecomunicações e de pacientes. No plano estrutural-organizacional, remete a uma configuração policêntrica, constituída por nós ou nódulos e por vínculos, relações, que os inter-relacionam.

A idéia de rede de conversações remete a um conjunto de relações ou interações cujas ligações são mediadas pela conversa entre atores envolvidos em um contexto compartilhado. No âmbito específico de um sistema de serviços de saúde, trata-se de um conjunto de relações não hierárquicas e interdependentes, vinculando gestores, profissionais/ prestadores e usuários mediante a Conversação para concretizar seus diversos interesses e promover a integração dos serviços. 
Nesta rede de conversação, não transitam apenas informações, mas sim atos de fala, que comprometem aqueles que os efetuam frente a si mesmos e aos outros. Pedidos e compromissos, ofertas e promessas, assentimentos e recusas, consultas e resoluções se entrecruzam e se modificam de forma recorrente na rede. Em particular, as promessas devem ser mantidas.

Segundo Teixeira (2003), em uma perspectiva de rede, o trabalho dos gestores e dos gerentes consiste não apenas em tomar decisões e resolver problemas sozinhos, mas, sobretudo, em animar e manter a rede de conversas onde são trocados os compromissos. Ele coordena as ações. Irá, sobretudo, tentar discernir, durante sua atividade comunicativa, as novas possibilidades que poderiam abrir-se à comunidade e ameaçariam reorientar algumas de suas finalidades, gerando assim novos circuitos de conversa.

A ideia é a de que uma rede integrada de serviços de saúde é operacionalizada por uma intensa rede de conversações, e sua análise constitui, portanto, um caminho possível para se compreender o funcionamento da rede de serviços. Os nós da rede de serviços são unidos pelas conversações que se travam durante as interações. Esta rede de conversações é composta de distintos pontos de conversação interligados, passíveis de serem mapeados e analisados.

Em síntese, de acordo com esse modelo, a integração dos serviços envolve atores, organizações e ações que são interdependentes. Essas interdependências são gerenciadas por mecanismos e processos de coordenação. Para coordenar suas ações, as pessoas se comunicam e, durante essa comunicação (conversação para coordenação de ações), decisões são tomadas e compromissos são gerados e negociados (promessas e declarações). A coordenação surge a partir dos compromissos originados das comunicações realizadas entre os participantes.

A comunicação está no centro da análise, pois uma abordagem exclusivamente estruturalfuncionalista realiza uma exclusão da (inter)subjetividade envolvida nos processos de coordenação. Além disso, conforme a Teoria dos Atos de Fala, a comunicação é ação. Assim, as conversações e os atos de fala nelas implicados tornam-se objeto privilegiado de análise da coordenação de ações entre serviços de saúde.

O interesse está centrado nas interações verbais, ou seja, nas formas concretas em que se manifestam as estratégias discursivas, construídas "interacionalmente" pelos participantes. Nesta perspectiva, os procedimentos metodológicos devem seguir uma abordagem pragmática, pois o interesse específico não é exatamente sobre a linguagem ou a definição dos significados fixos de palavras e enunciados, mas, sim, o uso dos enunciados implicados em uma interação comunicativa e nas condições de sua adequação.

O modelo de compreensão comunicativa da inter-relação entre comunicação, coordenação e integração corresponde ao que Max Weber chamou de "tipos ideais". Trata-se de uma abstração, uma ferramenta cognitiva usada para analisar a realidade. Ou seja, o modelo proposto não corresponde a uma descrição da realidade, mas serve para analisá-la. É uma ferramenta que, ao iluminar certos aspectos da realidade (no caso, a partir de uma compreensão comunicativa da coordenação), deixa outros aspectos desta mesma realidade de fora. Estas ferramentas são importantes nos esforços para tornar inteligível o pensamento e possibilitar uma narrativa coerente das evidências desordenadas da experiência social.

Para analisar as interações verbais que se dão nesta intrincada rede de conversações, a técnica de Análise de Conversação (AC) apresenta-se com uma ferramenta potente para se apreenderem aspectos centrais destas interações. A AC é uma prática que pertence à tradição anglo-saxã de Análise do Discurso (AD) e traz a ideia de que o analista pode observar a interação verbal e fazer interpretações justamente sobre aquilo que a linguagem está fazendo (Iñiguez, 2004).

A AC é um método de análise que estuda a ordem e a organização da ação social cotidiana por meio da análise rigorosa das conversações; analisa como os participantes organizam a interação de momento a momento. Está centrada na análise da linguagem na prática; lida com o discurso oral no contexto em que ocorre. Assim, não são desconsiderados os momentos reais da fala. Por meio da AC, busca-se captar o que dizem, contam ou fazem as pessoas e tudo o mais que é produzido pelos participantes em conversação. 


\begin{abstract}
A rigor, a AC é uma tentativa de responder a questões do tipo: como é que as pessoas se entendem ao conversar? Como sabem que estão se entendendo? Como sabem que estão agindo coordenada e cooperativamente? Como usam seus conhecimentos lingüísticos e outros para criar condições adequadas à compreensão mútua? Como criam, desenvolvem e resolvem conflitos interacionais? (Marcuschi, 2005, p.7)
\end{abstract}

$\mathrm{Na} A C$, são cinco as características básicas constitutivas, que devem ser objeto de observação:

- Interação entre, pelo menos, dois falantes.

- Ocorrência de, pelo menos, uma troca de falantes.

- Presença de uma sequência de ações coordenadas.

. Execução numa identidade temporal.

. Envolvimento numa "interação centrada".

\title{
Considerações finais
}

A integração em sistemas de serviços de saúde depende da qualidade dos processos de coordenação, e estes, por sua vez, dependem da eficácia dos processos comunicativos instaurados entre as pessoas no interior do sistema. Acredita-se que falhas na coordenação de serviços organizados de forma regionalizada podem ser devidas a deficiências dos processos comunicacionais e, portanto, novas práticas, baseadas no agir comunicativo, podem ser fundantes de novos patamares de efetividade da coordenação. Acredita-se também que a análise das redes de conversações possibilita a identificação e explicação de falhas existentes na rede de serviços de saúde.

A observação dos processos "interacionais" pelos quais se dá a coordenação de ações em sistemas de serviços de saúde pode representar uma opção para o desenho de estudos nesta área. A análise, por meio da AC, dos atos de fala predominantes nas redes de conversação e dos modos pelos quais as pessoas envolvidas em processos de coordenação organizam as interações é um caminho frutífero.

A escolha dos elementos e dos espaços de conversação a serem analisados dependerá do objeto e do escopo de cada pesquisa. Um trabalho empírico dentro desta perspectiva, realizado no Serviço de Atendimento Móvel de Urgência da Região Metropolitana II do Estado do Rio de Janeiro (SAMU Metro II/RJ), por exemplo, focou sua observação exclusivamente nas dimensões "sistema clínico" e "governança". A AC, voltada para a análise das interações intergestores e interserviços e das dificuldades de comunicação e suas implicações para os processos de coordenação, foi aplicada junto a dois arranjos constituídos dentro do SAMU Metro II/RJ, encarados como espaços centrais dos processos de coordenação: o colegiado de coordenadores e a central de regulação. Os resultados desta pesquisa trouxeram novos elementos para estudos sobre a coordenação em sistemas de serviços de saúde, que serão apresentados em outro artigo.

\section{Colaboradores}

Os autores trabalharam juntos em todas as etapas de produção do manuscrito. 


\section{Referências}

ARAGÃO, L. Habermas: filósofo e sociólogo do nosso tempo. Rio de Janeiro: Tempo Brasileiro, 2002.

ARTMANN, E. Démarche stratégique (gestão estratégica hospitalar): um enfoque que busca a mudança através da comunicação e solidariedade em rede. 2002. Tese (Doutorado) - Departamento de Medicina Preventiva, Faculdade de Ciências Médicas, Universidade de Campinas, Campinas. 2002.

ARTMANN, E.; RIVERA, F.J.U. A démarche stratégique (gestão estratégica hospitalar): um instrumento de coordenação da prática hospitalar baseado nos custos de oportunidade e na solidariedade. Cienc. Saude Colet., v.8, n.2, p.479-99, 2003.

AUSTIN, J.L. How to do things with words. New York: Oxford University Press, 1965. ECHEVERRIA, R. Ontologia del lenguaje. Santiago: Dolmen, 1997.

La empresa emergente, la confianza y los desafíos de la transformación. Santiago: Granica, 2000.

FARAJ, S.; XIAO, Y. Coordination in fast-response organizations. Manage. Sci., n.52, v.8, p.1155-69, 2006.

FEUERWERKER, L.C.M. et al. O processo de construção e de trabalho da Rede Unida. Saúde Deb., v.24, n.55, p.9-17, 2000.

FLORES, F. Inventando la empresa del siglo XXI. Santiago: Hachette, 1989.

FRANCO, T.B. As redes na micropolítica do processo de trabalho em saúde. In: PINHEIRO, R.; MATTOS, R.A. (Orgs.). Gestão em redes: práticas de avaliação, formação e participação na saúde. Rio de Janeiro: Cepesc-IMS/UERJ-Abrasco, 2006. p.459-474

GUITTEL, J.H. Coordinating mechanisms in care providers groups: relational coordination as a mediator and input uncertainty as a moderator of performance effects. Manage. Sci., v.48, n.11, p.1408-26, 2002a.

Relationships between service providers and their impact on customers. JSR, v.4, n.4, p.299-311, 2002b.

GUITTEL, J.H.; WEISS, L. Coordination networks within and across organizations: a multilevel framework. JMS, v.41, n.1, p.127-53, 2004.

HABERMAS, J. Racionalidade e comunicação. Lisboa: Edições 70, 2002a.

O discurso filosófico da modernidade. São Paulo: Martins Fontes, 2002b.

Teoría de la acción comunicativa. Madrid: Taurus, 2001. Tomos I e II.

HARTZ, Z.M.A.; CONTANDRIOPOULOS, A.P. Comprehensive health care and integrated health services: challenges for evaluating the implementation of a "system without walls". Cad. Saude Publica, v.20, supl.2, p.331-6, 2004.

IÑIGUEZ, L. (Org.) Manual de análise do discurso em Ciências Sociais. Petrópolis: Vozes, 2004.

LIMA, J.C. Agir comunicativo e coordenação em sistemas de serviços de saúde: um estudo no serviço de atendimento móvel de urgência da região metropolitana II do Estado do Rio de Janeiro. 2002. Tese (Doutorado) - Escola Nacional de Saúde Pública, Fundação Oswaldo Cruz, Rio de Janeiro. 2002.

LONGEST, B.; KLINGENSMITH, J. Coordination and communication In: SHORTELL, S.M.; KALUZNY, A.D. Health care management: a text in organization theory and behavior. New York: Delmar Publishers, 1988. p.230-45.

MARCUSCHI, L.A. Análise da conversação. São Paulo: Ática, 2005. 
MATURANA, H. Cognição, ciência e vida cotidiana. Belo Horizonte: Editora UFMG, 2001.

MITCHELL, S.M.; SHORTELL S.M. The governance and management of effective community health partnerships: a typology for research, policy, and practice. Milbank Q., v.78, n.2, p.241-89, 2000.

ROVERE, M. Redes: hacia la constituicción de redes en salud: los grupos humanos, las instituiciones, la comunidad. Rosario: Juan Lazarte, 1998.

SAFRAN, D.G.; MILLER, W.; BECKMAN, H. Organizational dimensions of relationshipcentered care: theory, evidence, and practice. JGIM, v.21, n1, p.9-15, 2005.

TEIXEIRA, R.R. O acolhimento num serviço de saúde entendido como uma rede de conversações. In: PINHEIRO, R.; MATTOS, R.A. (Orgs.). Construção da integralidade: cotidiano, saberes e práticas em saúde. Rio de Janeiro: UERJ/IMS/Abrasco, 2003. p.89-112.

LIMA, M.C.; RIVERA, F.J.U. Actuación comunicativa, redes de conversación y coordinación en servicios de salud: una perspectiva teórico-metodológica. Interface Comunic., Saude, Educ., v.13, n.31, p.329-42, out./dez. 2009.

En este artículo se discute un planteamiento teórico-metodológico para estudios en el área de la integración de servicios de salud, destacando el aspecto inter-subjetivo de los procesos de coordinación. Se parte del supuesto de que la coordinación de acciones y servicios de salud, proceso central de la integración, es esencialmente una acción comunicativa. Entre los aspectos metodológicos se destacan las potencialidades del Análisis de Conversaciones (AC) como herramienta para analizar las interacciones que se establecen en los procesos de coordinación de acciones y servicios de salud.

Palabras clave: Coordinación. Comunicación. Integración de servicios de salud. Análisis de conversación. Acción intersectorial. 